of air-screw is also subject to exhaustive tests to ensure that it is free from flutter before being used in machines.

In order to study vibration of aircraft in flight, very delicate instruments are necessary, and some of those developed at the Royal Aircraft Establishment were described by Major Carter. One vibrograpb designed there records the amplitude on a photographic film, and can be operated by the pilot during flight by remote control, and yet is vary compact and only weighs a little more than two pounds. To obtain records of air-screw blade tip vibration in flight, a camera is secured to and rotated with the hub, the motion of the blade tip being recorded on a film by means of the relative movement of a small electric light bulb cemented to the tip of the blade. Other modern methods include the use of photo-electric cells, the variation of the resistance of a body under stress and cathoderay oscillographs. It is evident that all the latest developments of the electrical and physical sciences are being adopted in these instruments.

One aspect of the vibration problem touched upon by all three speakers at the symposium was the use of elastic mountings for prime movers, and this is a device which is being developed very rapidly, particularly in the design of motor vehicles. Such mountings bring with them their own problems, but we can look forward to a progressive improvement in comfort in all forms of transport by the successful elimination of vibration through their use. Much remains to be done in this way, but it was evident from this discussion at Cambridge that the engineering profession is fully alive to the necessity and is progressing rapidly in all its many and varied branches.

\title{
Incremental Permeability of Special Steels
}

\section{$\mathrm{T}$} HE importance now attached to the incremental permeability of silicon-steel and of nickel-iron alloys arises from the use of these materials for the cores of transformers and chokes in communication apparatus. Under these conditions, the magnetization is due to a continuous steady current upon which a variation is imposed either by modulation or by separate coils carrying alternating currents. Generally, the amplitude of the imposed wave is not great enough to reduce the steady magneto-motive force to zero, so that the value of the induction rises and falls as the resultant magneto-motive force changes; but it does not reverse. The calculation of the induced electromagnetic force in a secondary coil in these circumstances is fraught with peculiar difficulties.

Adopting the usual convention and indicating magnetic induction by $B$, magnetic force by $H$ and permeability, $B / H$, by $\mu$, then if the mean value of $B$ is not high and its variation small, the mean ratio $B / H$ over the change will approach the value of $\mu$ as measured and used for simple alternating currents. But as the mean value about which $B$ varies gets nearer to the saturation region of the iron, and particularly when the imposed variation is large, not only does the mean value of $\mu$ fall rapidly, but also its instantaneous value varies considerably. The consequences are (1) that the prediction of a secondary induced E.M.F. is difficult; (2) that if the imposed variation of $H$ be sinusoidal, the wave form of $B$ will be distorted; (3) that if the imposed variation of $B$ be sinusoidal, the wave form of $H$ will be distorted; (4) that losses associated with given variations in $B$ and $H$ become difficult to measure and very different from those in the same iron under simple alternating current conditions. Yet makers of communication apparatus must know what results they may expect from the material that they purchase, so that some method of specifying and of testing the quality of steel for these purposes is badly needed.

This was pointed out by Dr. L. G. A. Sims at a meeting of Section G (Engineering) of the British Association at Norwich (1935), and he added that the British Standards Institution specification for transformer steels (No. 601), which had been published that year, would not serve for these new purposes. Section G, recognizing the importance of the matter, asked Dr. Sims to ascertain what was being done, both in England and abroad, and to report at the Blackpool meeting in the following year. As a result, a questionnaire containing eleven questions was sent out from the University of Birmingham, and an analysis of the replies was presented at the British Association meeting of 1936, representatives of the British Standards Institution being present. On seven of the questions, world opinion was sufficiently unanimous to enable Section $G$ to ask that tests should be begun upon silicon steels based upon an alternating current method of test, sinusoidal variation of induction at 50 cycles per second and with samples in the form of a ring.

In February, 1937, the British Standards Institution formed a committee to consider the drafting of a specification based upon these tests and the extension of such tests to cover the much 
wider conditions occurring in practice. The experimental work has been proceeding at both the University of Birmingham and the Northampton Institute, Clerkenwell, London, and substantial progress has been made by the British Standards Institution Committee. At the Nottingham meeting of the British Association (1937), when papers embodying the results to date were read, it became evident that methods of defining and measuring the harmonic content of a distorted wave were needed, and that there were difficulties in connexion with symbols. Two methods of measuring the wave distortion were given, and the experiments by Greig and Parton proved that this factor could be determined either by a filterbridge or by an alternating current potentiometer.

The papers presented at the Cambridge meeting of the British Association, before a joint meeting of Section A (Mathematics and Physics) and Section G, showed a great extension of the experimental work by the teams in Birmingham and London; and in addition, Mr. D. C. Gall gave an account of the manner in which academic instruments could be adapted to commercial requirements; while Mr. C. E. Webb outlined the rapid advances that are being made in alloys suitable for transformers and communication apparatus.

The subsequent discussion was remarkable for the comments by makers and users of the steels under test; it is a pity that more time could not be allotted for valuable contributions of this kind which the British Association, and perhaps the British Association alone, can evoke. In the matter of symbols and definitions, little progress was made, the only helpful remarks coming from Prof. G. W. O. Howe, who showed that, in Germany, both definitions of 'distortion factor' suggested by Sims and Greig were used rather indiscriminately with little inconvenience. The official view of the British Standards Institution was expressed by Mr. J. F. Stanley. He emphasized the role of that Institution as a body holding a balance between research and utility, and therefore bound to search for a practical specification. He remarked upon the fact that the research work in this instance was unique in that it is in the hands of educational institutions and not commercial research organizations. He welcomed as a guide the broad discussion at the British Association, but held that actual decisions must be left to the Institution Committee. Many references were made to the new materials mentioned by Mr. Webb. More than one speaker commented upon the amazingly high permeabilities which he had disclosed. On the other hand, doubt was expressed as to whether such values would be found under polarized conditions, for Parton and Glazier have shown that there is an actual reversal of the usual order of permeability of annealed and unannealed specimens when they are polarized. Again, in connexion with the effect of impurities in alloys, one speaker (Mr. W. Randall) said that atomic order has been found very important, especially in the case of molybdenum and of chromium, and that the direction of the crystal axes also must not be overlooked. Others warned the investigators that results obtained on silicon steel would not apply to nickel iron alloys; and, as Mr. Ronald Sankey reminded the meeting, the new cold-rolled silicon steels may call for special attention.

Two general suggestions of great value emerged from the steel makers and users who were present. The first, stressed by Mr. Ronald Sankey and Mr. K. Macfadyen, was to the effect that tests suitable for quality control and acceptanceroutine tests in fact-should be kept separate from tests devised to determine the exact properties of the materials. This, of course, is bound up with the question of apparatus suitable for routine work; in which connexion, as an addition to Mr. Gall's proposals, both the disk magnetometer and the 'Ferrometer' were mentioned. It is one thing to deal with a few ounces in the laboratory ; quite another to deal with tests on 50 tons of stampings, and no doubt the industrialists were right to direct attention to this question of perspective. Dr. E. H. Rayner, of the National Physical Laboratory, thinks that it might be advantageous to put forward a 'temporary specification' that could be tried and revised after a year or so.

The other suggestion was a plea that any specification should so far as possible be international. Section G has from the first kept this in mind, as is shown by the wide dissemination of the Birmingham questionnaire; but the duty of seeing that British steel-makers are not penalized in the world's markets is a new aspect of this question which the British Standards Institution must not neglect.

The discussion very properly laid bare the great difficulties, both academic and practical, with which this subject bristles. It is clear that progress is being made, and nothing but good can result from such an open and free debate. At the same time, the whole development shows a section of the Association moving in a new and useful direction. For, not content with recording the advancement of its science for the benefit of the public, it has pointed out to an industry a region in which scientific advance is needed. Further, with the friendly co-operation of that industry, it has initiated a movement which will help manufacturers to specify and to test the magnetic qualities of their most important raw material. 